My cooperation with Gerta Vrbová

Eur J Transl Myol 31 (1): 9585, 2021 doi: 10.4081/ejtm.2021.9585

\title{
The significance of Gerta Vrbová's low-frequency stimulation experiment
}

\author{
Dirk Pette
}

Department of Biology, University of Konstanz, Konstanz, Germany

This article is distributed under the terms of the Creative Commons Attribution Noncommercial License (CC BY-NC 4.0) which permits any noncommercial use, distribution, and reproduction in any medium, provided the original author(s) and source are credited.

\begin{abstract}
An inspiring scientific cooperation has come to an end, when Gerta Vrbová, an internationally renowned researcher in the field of neuromuscular interactions, passed away on October 2, 2020. Comparative EMG studies had led Gerta to suggest that different contractile properties of fastand slow-twitch muscle fibers relate to specific firing patterns of their motoneurones. In support of her hypothesis, long term stimulation of fast-twitch muscles with a stimulus pattern resembling that of slow motoneurones, were shown to induce a pronounced fast-to-slow shift in contractile properties. In our cooperation which started in 1970, and also in cooperation with others, Gerta's experiment proved to be an ideal model for the study of neurally controlled changes in phenotype characteristics at various levels of molecular and cellular organization, their time courses and ranges. It has become most important in basic research on the adaptive potential or plasticity of muscle.
\end{abstract}

Key Words: cardiomyoplasty; chronic electrical stimulation; muscle plasticity; neural control; skeletal muscle fiber types

Eur J Transl Myol 31 (1): 9585, 2021 doi: 10.4081/ejtm.2021.9585

It was with great sadness that I learned of Gerta's passing on October $2^{\text {nd }}, 2020$. Only a week before, we had made one of our irregular phone calls and discussed the possibility of seeing each other in the near future. It was our last conversation.

Ever since we met and started our cooperation, Gerta and I have been connected in an almost life-long friendship.

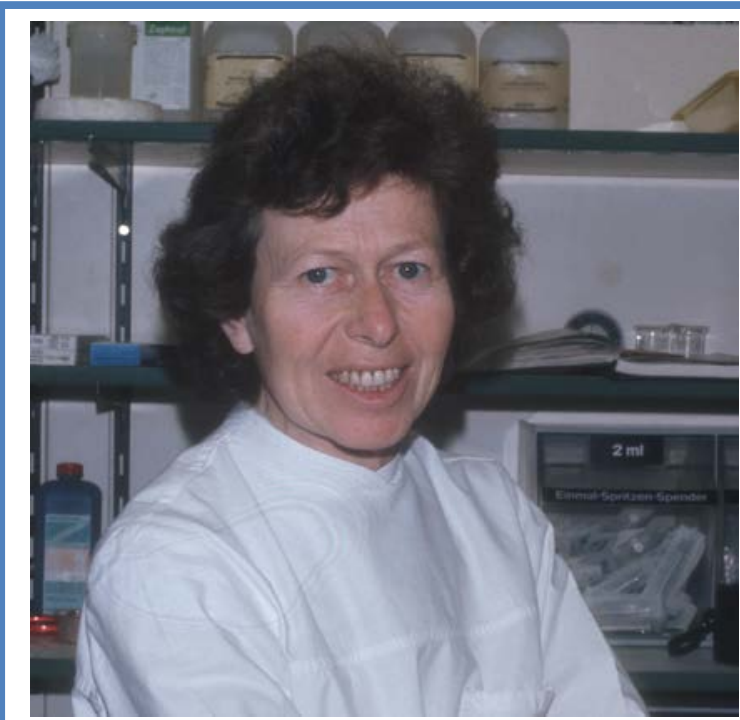

Fig. 1. Gerta Vrbová, Konstanz 1970.
When I arrived on my first visit to Birmingham 50 years ago, I was received with so much warmth and cordiality that I felt immediately at home and amongst friends. Gerta must have made similar experiences, when some time later she visited Konstanz and met Fanny, my wife with whom she formed a lasting friendship as well. Numerous mutual visits followed; they were part of our collaborative experiments and included coworkers from

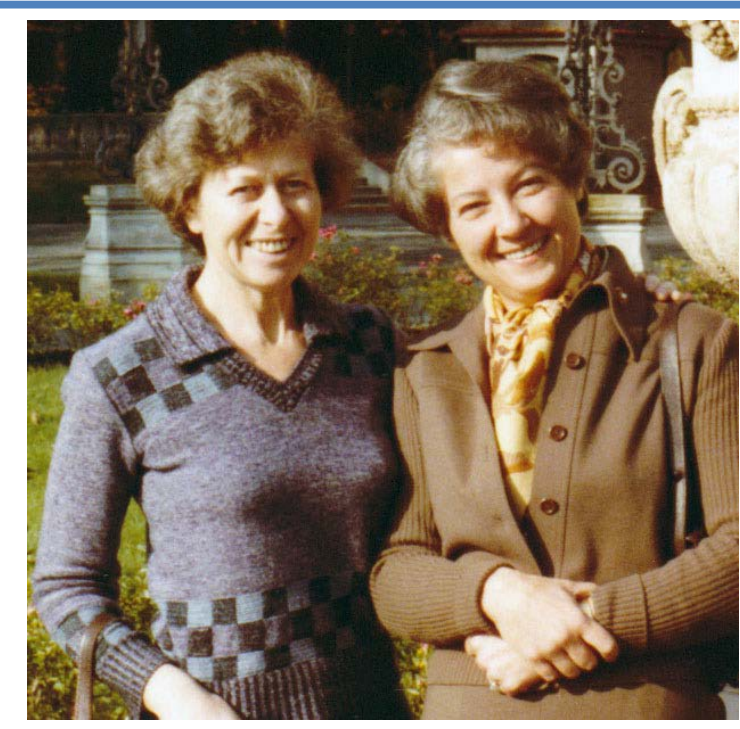

Fig 2. Gerta Vrbová, Fanny Pette, Konstanz 1976. 


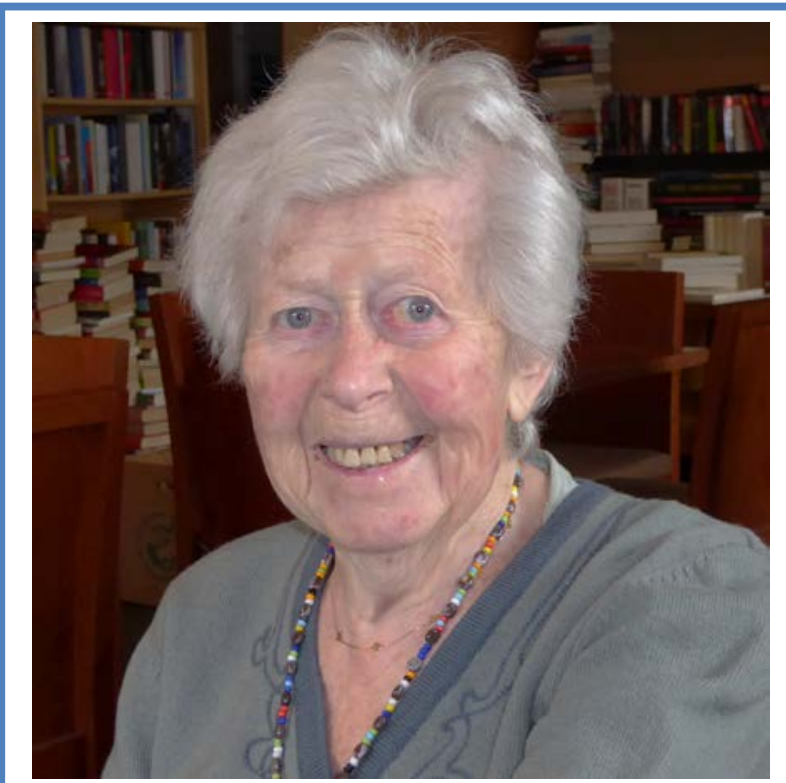

Fig 3. Gerta Vrbová, Visit to Reichenau, May 2015.

both laboratories. We seized every opportunity for getting together, wrote original articles and reviews or attended scientific meetings all over the world. Looking back 50 years, I realize what impact our cooperation and friendship had on my scientific life.

Unaware of each other's work, we had come into contact through a workshop held 1969 in Prague where Ernest Gutmann and Sidney Hilton, Gerta's second husband, suggested that cooperation with Gerta would be an absolute necessity. Gerta had gained new insights into nerve-muscle interactions by comparative EMG recordings from motor units of mammalian slow- and fast-twitch muscles. Her observations led her to suggest that phenotypic properties of skeletal muscle are under the control of specific firing patterns of their motoneurones. ${ }^{1}$ Using an implanted stimulator designed by Stanley Salmons, she tested her hypothesis by exposing fast muscles of cat and rabbit to stimulus patterns resembling that of slow motoneurones. Pronounced fast-to-slow transitions of contractile properties were indeed observed under the influence of indirect chronic low-frequency stimulation. ${ }^{2,3}$

Comparative studies performed at the same time in my laboratory in Munich and later in Konstanz had shown that enzyme activities of energy metabolism exist as specific metabolic profiles in functionally different vertebrate and invertebrate muscles. ${ }^{4,5}$ Furthermore, cross-re-innervation of rabbit fast- and slow-twitch muscles induced pronounced shifts of their metabolic profiles in opposite directions. ${ }^{6}$

As shown in a first joint study of our laboratories, chronic indirect stimulation of fast-twitch rabbit muscles with a slow motoneurone-like impulse pattern led to a change of the muscle's metabolic profile similar to that after fast-toslow cross-re-innervation. ${ }^{7}$ The changes indicated a shift

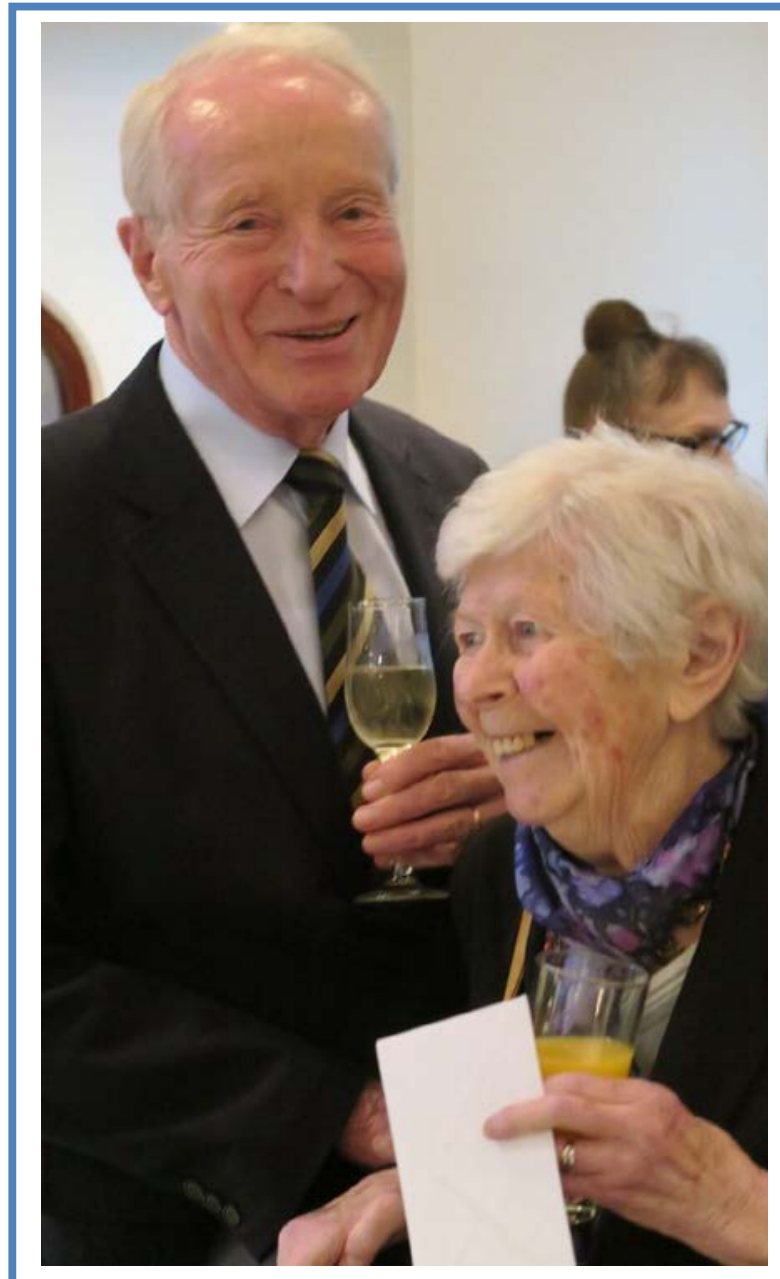

Fig 4. Gerta Vrbová and Dirk Pette at birthday party, Penang Satay House. London November 26, 2016.

of energy metabolism from anaerobic towards aerobicoxidative catabolic pathways as reflected by pronounced decreases in enzyme activities of glycogenolysis and glycolysis and several fold increases in mitochondrial enzyme activities of terminal substrate oxidation.

These first observations not only supported Gerta's hypothesis but also suggested application of her experiment to basic research on muscle plasticity. Chronic stimulation would allow changes in phenotype expression in a terminally differentiated post-mitotic tissue responding to altered functional demands. Moreover, chronic stimulation would offer the possibility of investigating nature, hierarchy and sequence of changes at different levels of cellular and molecular organization. Moreover, supramaximal long-term stimulation would disclose the full range of adaptations because contrary to exercise where motor units are recruited in a hierarchical order, all motor units of the target muscle are simultaneously activated. Systemic influences such as stress, changes in hormone homeostasis, etc., would be of little importance as they 
would equally affect stimulated and unstimulated contralateral muscles, the latter serving as intra-animal control. Finally, chronic stimulation could be performed under extensively standardized conditions with regard to duration of supramaximal activation by defined impulse patterns, etc. Implementing and adjusting these conditions has been greatly improved by the development of set-ups for tele-stimulation.

The numerous results from studies based on Gerta's experiment have been listed in several review articles ${ }^{8-10}$ and do not have to be repeated here. In summary, they showed that chronic low-frequency stimulation induces altered expression levels and sequential isoform exchanges of the major myofibrillar proteins, soluble and membrane-bound $\mathrm{Ca}^{2+}$-regulatory proteins and key enzymes of anaerobic and aerobic pathways of energy metabolism. Combining results from rat and rabbit muscles, these transitions follow specific time courses and occur in a regular manner with the appearance of intermediate hybrid fiber types. Increases in capillary density were shown to precede the rise in aerobicoxidative potential of energy metabolism. Altered $\mathrm{Ca}^{2+}$ transients and pronounced fluctuations in energy-rich phosphates detected by single fiber analysis, pointed to their possible role as signals initiating the process of fiber transformation. Complementary studies revealed activation of satellite cells indicating their role in fiber type transitions and fiber degeneration-regeneration processes. Pilot studies on young and very old rats provided data suggesting the adaptability of skeletal muscle staying unaltered during aging.

On the basis of an idea which was daring at its time, Gerta had devised an experiment which resulted in far more than in support of her hypothesis, it became of great importance for research on nerve-muscle interactions, especially for basic research on muscle plasticity, its responsiveness to altered functional demands. Her experiment was a present to the scientific community, to me and others who recognized its value and exploited its possibilities. One hundred and twenty original publications and nineteen doctoral dissertations originated in my laboratory within 45 years, all of them based on Gerta's original experiment.

Although Gerta's merits have been widely recognised, it is my intention here to emphasise once again the importance of her stimulation experiment. In my opinion it is her most important contribution

Thank you, Gerta!

\section{Acknowledgments}

A\&C M-C Foundation for Translational Myology, Padova, Italy and PAGEpress, Scientific Publications, Pavia, Italy sponsored this Obituary.

\section{Funding None}

\section{Conflict of Interest}

The author declares no competing interests.

\section{Ethical Publication Statement}

I confirms that I have read the Journal's position on issues involved in ethical publication and affirms that this report is consistent with those guidelines.

\section{Corresponding Author}

Dirk Pette, Department of Biology, University of Konstanz, D-78457 Konstanz, Germany.

E-mail: dirk.pette@gmail.com

\section{References}

1. Vrbová G. The effect of motoneurone activity on the speed of contraction of striated muscle. J Physiol. 1963 Dec;169(3):513-26. doi: 10.1113/ jphysiol.1963.sp007276.

2. Salmons S, Vrbová G. Changes in the speed of mammalian fast muscle following longterm stimulation. J Physiol. 1967 Sep;192(2):39P-40P.

3. Salmons S, Vrbová G. The influence of activity on some contractile characteristics of mammalian fast and slow muscles. J Physiol. 1969 May;201(3):53549. doi: 10.1113/jphysiol.1969.sp008771.

4. Pette D. Plan und Muster im zellulären Stoffwechsel. Naturwissenschaften. 1965; 52:597616.

5. Bass A, Brdiczka D, Eyer P, Hofer S, Pette D. Metabolic differentiation of distinct muscle types at the level of enzymatic organization. Eur J Biochem. 1969 Sep;10(2):198-206. doi: 10.1111/j.1432-1033 .1969.tb00674.x.

6. Golisch G, Pette D, Pichlmair H. Metabolic differentiation of rabbit skeletal muscle as induced by specific innervation. Eur J Biochem. 1970 Sep;16(1):110-6. doi: 10.1111/j.1432-1033.1970. tb01060.x.

7. Pette D, Smith ME, Staudte HW, Vrbová G. Effects of long-term electrical stimulation on some contractile and metabolic properties of fast rabbit muscles. Pflügers Arch. 1973 Feb 6;338(3):257-72. doi: 10.1007/BF00587391.

8. Pette D, Vrbová G. Adaptations of mammalian muscle fibers to chronic electrical stimulation. Rev Physiol Biochem Pharmacol. 1992;120:115-202. doi: 10.1007/BFb0036123..

9. Pette D, Vrbová G. Invited review: What does chronic electrical stimulation teach us about muscle plasticity? Muscle Nerve 1999 Jun;22(6):666-77. doi: 10.1002/(sici)1097-4598(199906)22:6<666:: aid-mus3>3.0.co;2-z..

10. Pette D, Vrbová G. The contribution of Neuromuscular Stimulation in Elucidating Muscle Plasticity Revisited. Eur J Transl Myol. 2017 Feb 24;27(1):6368. doi: 10.4081/ejtm.2017.6368.

Submitted: January 3, 2021 Accepted for publication: January 3, 2021 